\title{
Bosentan and macitentan prevent the endothelial-to-mesenchymal transition (EndoMT) in systemic sclerosis: in vitro study
}

Claudio Corallo ${ }^{1 *}$, Maurizio Cutolo ${ }^{2}$, Bashar Kahaleh ${ }^{3}$, Gianluca Pecetti ${ }^{4}$, Antonio Montella ${ }^{1}$, Chiara Chirico ${ }^{1}$, Stefano Soldano ${ }^{2}$, Ranuccio Nuti ${ }^{1}$ and Nicola Giordano ${ }^{1}$

\begin{abstract}
Background: Systemic sclerosis (SSc) is characterized by early vascular abnormalities and subsequent fibroblast activation to myofibroblasts, leading to fibrosis. Recently, endothelial-to-mesenchymal transition (EndoMT), a complex biological process in which endothelial cells lose their specific markers and acquire a mesenchymal or myofibroblastic phenotype, has been reported in SSc. In the present study, we evaluated the ability of endothelin-1 (ET-1) dual receptor antagonists bosentan (BOS) and macitentan (MAC) to antagonize EndoMT in vitro.

Methods: Ten women with limited SSc were enrolled. They underwent double skin biopsy (affected and nonaffected skin). Fibroblasts and microvascular endothelial cells (MVECs) were isolated from biopsies. We performed mono- or coculture of MVECs (isolated from nonaffected skin) with fibroblasts (isolated from affected skin and stimulated with ET-1 and transforming growth factor beta [TGF- $\beta]$ ). In cocultures, the MVEC layer was left undisturbed or was preincubated with BOS or MAC. After $48 \mathrm{~h}$ of coculture, MVECs were analyzed for their tube formation ability and for messenger RNA and protein expression of different vascular (CD31, vascular endothelial growth factor-A [VEGF-A], VEGF-A165b) and profibrotic (alpha-smooth muscle actin [a-SMA], collagen type I [Col I], TGF- $\beta$ ) molecules.

Results: After 48 h, MVECs showed a reduced tube formation ability when cocultured with SSc fibroblasts. CD31 and VEGF-A resulted in downregulation, while VEGF-A165b, the antiangiogenic isoform, resulted in upregulation. At the same time, mesenchymal markers a-SMA, Col I, and TGF- $\beta$ resulted in overexpression in MVECs. Tube formation ability was restored when MVECs were preincubated with BOS or MAC, also reducing the expression of mesenchymal markers and restoring CD31 expression and the imbalance between VEGF-A and VEGF-A165b.

Conclusions: With this innovative EndoMT in vitro model realized by coculturing nonaffected MVECs with affected SSC fibroblasts, we show that the presence of a myofibroblast phenotype in the fibroblast layer, coupled with an ET-1-TGF- $\beta$ synergic effect, is responsible for EndoMT. BOS and MAC seem able to antagonize this phenomenon in vitro, confirming previous evidence of endothelium-derived fibrosis in SSc and possible pharmacological interference.
\end{abstract}

Keywords: Systemic sclerosis, EndoMT, Microvascular endothelial cells, Bosentan, Macitentan

\footnotetext{
*Correspondence: corallo.claudio@gmail.com

${ }^{1}$ Scleroderma Unit, Department of Medicine, Surgery and Neurosciences,

University of Siena, 53100 Siena, Italy

Full list of author information is available at the end of the article
} 


\section{Background}

Systemic sclerosis (SSc) is an autoimmune connective tissue disease characterized by cutaneous and visceral fibrosis coupled with widespread vascular pathology [1]. The first sign occurring in 90-98 \% of patients with SSc is Raynaud's phenomenon, an abnormal reactivity of digital microvasculature under cold and other stimuli $[2,3]$, which highlights the central role of microvascular damage in the pathogenesis of SSc [4]. In SSc, imbalance of endothelial signals, such as increased release of vasoconstrictory endothelin 1 (ET-1), thromboxane, and thrombomodulin, and reduction of prostaglandin $\mathrm{I}_{2}$ and nitric oxide are signs of the endothelial injury [5]. Although different molecules have been identified as key effectors of vascular remodeling in SSc, such as ET-1 and transforming growth factor beta (TGF- $\beta$ ), the mechanisms underlying SSc vasculopathy remain poorly understood [6]. There are two important issues: how the vascular damage can lead to the fibrotic process and the relationship between vessel disappearance and myofibroblast activation [7]. In fact, myofibroblasts in fibrotic tissues are derived from at least three sources: expansion and activation of resident tissue fibroblasts, transition of epithelial cells into mesenchymal cells (epithelialto-mesenchymal transition [EMT]), and tissue migration of bone marrow-derived circulating fibrocytes [8]. Recently, endothelial-to-mesenchymal transition (EndoMT), a newly recognized type of cellular transdifferentiation, has emerged as another possible source of tissue myofibroblasts [9]. EndoMT is a complex biological process in which endothelial cells lose their specific markers and acquire a mesenchymal or myofibroblastic phenotype and express mesenchymal cell products such as alpha smooth muscle actin ( $\alpha$-SMA) and collagen type I (Col I) $[8,9]$. Despite evidence suggesting that EndoMT is involved in not only pathological [10-12] but also physiological conditions
[13], the underlying molecular mechanisms involved in this process are largely unknown. Similarly to EMT, EndoMT can be induced by TGF- $\beta$ [14]. Of note, the same molecule is considered, together with ET-1, to be a pivotal player in the developmental of SSc fibrosis [15]. It is well documented that the activation of TGF- $\beta$ intracellular transcription factors is responsible of the production of other fibrotic molecules, such as ET-1 [16]. Moreover, TGF- $\beta$-induced ET-1 release has been associated with the fibrotic response of skin and lung SSc fibroblasts [17]. In the present study, we established an in vitro model of EndoMT made up of fibroblast and microvascular endothelial cell (MVEC) cocultures. Considering the synergistic action of ET-1 and TGF- $\beta$ to induce EndoMT, we investigated the potential of ET-1 dual receptor antagonists bosentan (BOS) and macitentan (MAC) to antagonize EndoMT in our in vitro coculture model.

\section{Methods \\ Patient enrollment, skin biopsy, and cell isolation Patients}

We enrolled ten women (age $55.7 \pm 12.3$ years, disease duration $8.3 \pm 1.8$ years) affected by limited SSc (ISSc) in accordance with the description of LeRoy and colleagues [18] and who fulfilled the 2013 American College of Rheumatology/European League Against Rheumatism diagnostic criteria for SSc [19]. Table 1 shows the major demographic and clinical characteristics of these patients. We performed skin biopsies by using a 3-mm punch on affected skin graded as 2 according to modified Rodnan skin score (mRSS) [20]. Unaffected areas of midforearm skin from the same patients with ISSc were also taken. The unaffected skin of patients with ISSc was defined by clinical palpation (graded as 0 according to mRSS) and by histological examination that excluded SSc-related lesions.

Table 1 Clinical parameters of patients with limited systemic sclerosis

\begin{tabular}{llllllll}
\hline Patient & Age (years) & Sex & Disease duration (years) & Digital ulcers & PAH & mRSS/score at affected skin biopsy & ANA-ENA \\
\hline 1 & 64 & F & 8 & no & no & $10 / 2$ & Anticentromere-CenpB \\
2 & 35 & F & 9 & no & no & $09 / 2$ & Anticentromere-CenpB \\
3 & 72 & F & 11 & yes & yes & $13 / 2$ & Anticentromere-CenpB \\
4 & 49 & F & 7 & no & no & $10 / 2$ & Anticentromere-CenpB \\
5 & 37 & F & 5 & no & no & $10 / 2$ & Anticentromere-CenpB \\
6 & 52 & F & 10 & no & no & $11 / 2$ & Anticentromere-CenpB \\
7 & 59 & F & 8 & yes & yes & $13 / 2$ & Anticentromere-CenpB \\
8 & 66 & F & 9 & no & no & $09 / 2$ & Anticentromere-CenpB \\
9 & 58 & F & 6 & no & no & $10 / 2$ & Anticentromere-CenpB \\
10 & 65 & F & 10 & no & no & $10 / 2$ & Anticentromere-CenpB \\
Mean (SD) & $55.7(12.3)$ & & $8.3(1.8)$ & & & & \\
\hline
\end{tabular}

Abbreviations: ANA Antinuclear antibodies, ENA Extractable nuclear antigens, CenpB Centromere protein B, mRSS Modified Rodnan skin score, PAH Pulmonary arterial hypertension

Patients discontinued corticosteroids, oral vasodilators, intravenous prostanoids, and other disease-modifying drugs at least 1 month before skin biopsies 


\section{Fibroblast isolation and cultures}

Fibroblasts were isolated from skin specimens by enzymatic digestion. Briefly, explants were de-epidermized using a dispase solution (dispase activity $14 \mathrm{U} / \mathrm{ml}$; Sigma-Aldrich, St. Louis, MO, USA) for $2 \mathrm{~h}$ at $37^{\circ} \mathrm{C}$ and then were dissolved into a collagenase III solution $(2.4 \mathrm{U} / \mathrm{ml}$; Sigma-Aldrich) for 30 minutes. Fibroblasts obtained were passaged twice and cultured at a density of $1 \times 10^{6}$ cells per flask in DMEM (Sigma-Aldrich) supplemented with penicillin $(100 \mathrm{U} / \mathrm{ml}$; Sigma-Aldrich), streptomycin (100 $\mu \mathrm{g} / \mathrm{ml}$; Sigma-Aldrich), amphotericin B $(0.25 \mu \mathrm{g} / \mathrm{ml}$; Sigma-Aldrich $)$, glutamine (2 mM; Sigma-Aldrich), and $10 \%$ FBS (Sigma-Aldrich), followed by incubation at $37{ }^{\circ} \mathrm{C}$ in an atmosphere of $5 \%$ $\mathrm{CO}_{2}$ and $95 \%$ air until confluence (1 week) in $75-\mathrm{cm}^{2}$ flasks (BD Costar, Cambridge, MA, USA). Viability was estimated by trypan blue staining (Sigma-Aldrich). Fibroblasts were used at third passage (P3) for cocultures.

\section{MVEC isolation and cultures}

Biopsy samples were washed with PBS (Sigma-Aldrich) and placed into a 50-ml tube (BD Costar) containing $15 \mathrm{ml}$ of trypsin (Sigma-Aldrich) for digestion at $37^{\circ} \mathrm{C}$ for 45 minutes. Cells were cultured in EGM-MV microvascular endothelial cell growth medium (Lonza, Walkersville, MD, USA) at $37{ }^{\circ} \mathrm{C}$ in an atmosphere of $5 \% \mathrm{CO}_{2}$ and $95 \%$ air. Before reaching confluence, the heterogeneous pool of cells was exposed to a cluster of differentiation 31 (CD31)-positive selection by using the DynaBeads magnetic CD31 MicroBeads cell-sorting system (Invitrogen, Carlsbad, CA, USA) following the manufacturer's instructions. After removing CD31-negative cells, only cells positive for CD31 were collected. MVECs obtained were used at P3 for mono- and cocultures.

\section{EndoMT coculture model}

In order to set up an in vitro model of EndoMT, fibroblasts isolated from affected skin biopsies and MVECs isolated from unaffected skin areas were cocultured in Transwell $^{\circ} 12$-well plate inserts $(0.4-\mu \mathrm{m}$ pore size; Corning, Corning, NY, USA). Fibroblasts and MVECs were seeded in cocultures in a 1:3 ratio: fibroblasts in transwell inserts and MVECs in the bottom of the wells. The following cocultures of affected fibroblasts with affected MVECs (positive control) and unaffected fibroblasts with unaffected MVECs (negative control) were also performed. The fibroblast layer of the EndoMT model was incubated with $100 \mathrm{nM} \mathrm{ET-} 1$ and $5 \mathrm{ng} / \mathrm{ml}$ TGF- $\beta$ for $48 \mathrm{~h}$ to permanently maintain the myofibroblast phenotype in culture. The MVEC layer of the EndoMT model was left undisturbed for $48 \mathrm{~h}$ or preincubated with $10 \mu \mathrm{M}$ BOS or $1 \mu \mathrm{M}$ MAC [6] $1 \mathrm{~h}$ before treating the fibroblast layer with ET-1 and TGF- $\beta$.

\section{Tube formation ability of MVECs}

Tube formation ability was evaluated using a Matrigel assay. Matrigel (BD Biosciences, San Jose, CA, USA) was used at $8.6 \mathrm{mg} / \mathrm{ml}$ in a 1:1 dilution with EGM2-MV (Lonza), without any supplement. MVECs were labeled, before coculture in Matrigel, with the red fluorescent dye PKH26 (Sigma-Aldrich) following the manufacturer's instructions. After $48 \mathrm{~h}$ of mono- or coculture with fibroblasts, MVECs tube total length in each well, calculated as cells per millimeter, were calculated by using a Zeiss AxioPlan2 fluorescence microscope equipped with AxioVision 4.6 for Windows software (Carl Zeiss Vision $\mathrm{GmbH}$, Hallbergmoos, Germany). The number of branching points was calculated using MetaMorph ${ }^{\circ}$ software for Windows (Molecular Devices, Sunnyvale, CA, USA). The number of tubes formed was quantitated by an observer blinded to the experimental groups.

\section{Western blot analysis}

Collected MVECs were centrifuged at $1500 \mathrm{rpm}$ for $10 \mathrm{mi}-$ nutes at room temperature. Pellets were then suspended in PBS buffer and centrifuged at $3000 \mathrm{rpm}$ for 20 minutes at $4{ }^{\circ} \mathrm{C}$. The obtained pellets were then suspended in radioimmunoprecipitation assay buffer (Sigma-Aldrich) containing protease inhibitor cocktail (Sigma-Aldrich) for 40 minutes in ice and then centrifuged at $15000 \mathrm{rpm}$ for 30 minutes at $4{ }^{\circ} \mathrm{C}$. After centrifugation, supernatants were collected, and protein concentration was calculated according to Bradford assay [21]. About $20 \mu \mathrm{g}$ of cell lysate proteins for each lane were resolved in a $12 \%$ SDSPAGE buffer according to Laemmli [22]. The bands were transferred from the gels to polyvinyl difluoride membranes using the iBlot ${ }^{\text {tux }}$ Dry Blotting System (Invitrogen). The endothelial markers chosen for MVECs were rabbit polyclonal anti-CD31 (Abcam, Cambridge, UK), rabbit polyclonal anti-vascular endothelial growth factor A (antiVEGF-A) (Abcam), and rabbit polyclonal anti-VEGFA165b (Abcam). The mesenchymal markers chosen for MVECs were rabbit polyclonal anti- $\alpha$-SMA (Abcam), rabbit polyclonal anti-Col-I (Abcam), and rabbit polyclonal anti-TGF- $\beta$ (Abcam). Incubation was carried out using iBlot ${ }^{\circ}$ Western Detection Kit (Invitrogen). The load control protein used was beta actin (Abcam). The bound primary antibodies were detected using antirabbit immunoglobulin G alkaline phosphate conjugate (Invitrogen) and visualized using a ChemiDoc ${ }^{\text {Tax }}$ XRS 170-870 molecular imager (Bio-Rad Laboratories, Hercules, CA, USA) and quantified by using Quantity One software (Bio-Rad Laboratories).

\section{RNA isolation and quantitative real-time polymerase chain reaction}

MVECs were collected in TRIzol reagent (Sigma-Aldrich). Total RNA was extracted following the manufacturer's 
instructions. The total RNA content of the samples was quantified by measuring the absorbance at $260 \mathrm{~nm}$ using an Ultrospec 2000 spectrophotometer (Amersham Pharmacia Biotech, Piscataway, NJ, USA). The RNA was then reverse-transcribed using a random hexamer MultiScribe enzyme (Applied Biosystems, Foster City, CA, USA). Quantitative real-time polymerase chain reactions (qRT-PCR) were run in the StepOne Real-Time PCR System (Applied Biosystems) using TaqMan chemistry (Invitrogen). Two microliters of complementary DNA in a final volume of $20 \mu \mathrm{l}$ were amplified using the $20 \times$ Assays-on-Demand gene expression assay mix (Applied Biosystems). Specific primers were designed on the basis of the reported sequences (National Center for Biotechnology Information PrimerBank): $\alpha$-SMA: 5 '-CGGT GCTGTCTCTCTATGCC-3' (forward) and 5' -CGCTCA GTCAGGATCTTCA-3' (reverse); Col I: 5' -AGGGCCAA GACGAAGACAGT-3' (forward) and 5' -AGATCACGTC ATCGCACAACA-3' (reverse); TGF- $\beta$ : $5^{\prime}$-CTAATGGTG GAAACCCACAACG-3' (forward) and 5'-TATCGCCAG GAATTGTTGCTG-3' (reverse); CD31: 5'-AACAGTGT TGACATGAAGAGCC-3' (forward) and 5'-TGTAAAACAGCACGTCATCCTT-3' (reverse); VEGF-A: 5' -AGGG CAGAATCATCACGAAGT-3' (forward) and 5'-GCTGC GCTGATAGACATCCA-3' (reverse); VEGF-A165b: 5' -G AGCAAGACAAGAAAATCCC-3' (forward) and $5^{\prime}$ GTGAGAGATCTGCAAGTACG-3' (reverse). TaqMan probes, specific primers and ribosomal $18 \mathrm{~S}$, selected as a housekeeping gene, were purchased from Applied
Biosystems. Messenger RNA (mRNA) levels were normalized to those of $18 \mathrm{~S}$.

\section{Statistical analysis}

Prism $6.0^{\circ}$ for Windows software (GraphPad Software, La Jolla, CA, USA) was used for statistical analysis. Data regarding Western blot analyses are expressed as mean \pm $\mathrm{SD}$ of three technical replicates evaluated by analysis of variance (ANOVA) and Tukey's multiple-comparisons test. Significance was set at $p<0.05$. Data related to the number of branching points are expressed as mean $\pm \mathrm{SD}$, while those related to tube formation ability and to qRT-PCR are expressed as median (range) of six biological replicates. Because the data followed a nonparametric distribution, the Mann-Whitney $U$ test was thought to be appropriate for the analyses. Significance was set at $p<0.05$.

\section{Results}

Tube formation ability of MVECs

In our in vitro EndoMT model, MVECs cocultured with affected fibroblasts (stimulated with ET-1 and TGF- $\beta$ ) showed a significant impairment in tube formation, probably due to the persistent stimulation of the myofibroblast phenotype (Fig. 1a). After $48 \mathrm{~h}$ of coculture, MVECs statistically reduced their ability to form tubular structures in untreated samples. In fact, as shown in Fig. 1b, the analysis of tube formation ratio evidenced significant improvement in tube formation when MVECs were preincubated with $\operatorname{BOS}(p<0.01)$ and MAC $(p<0.01)$.

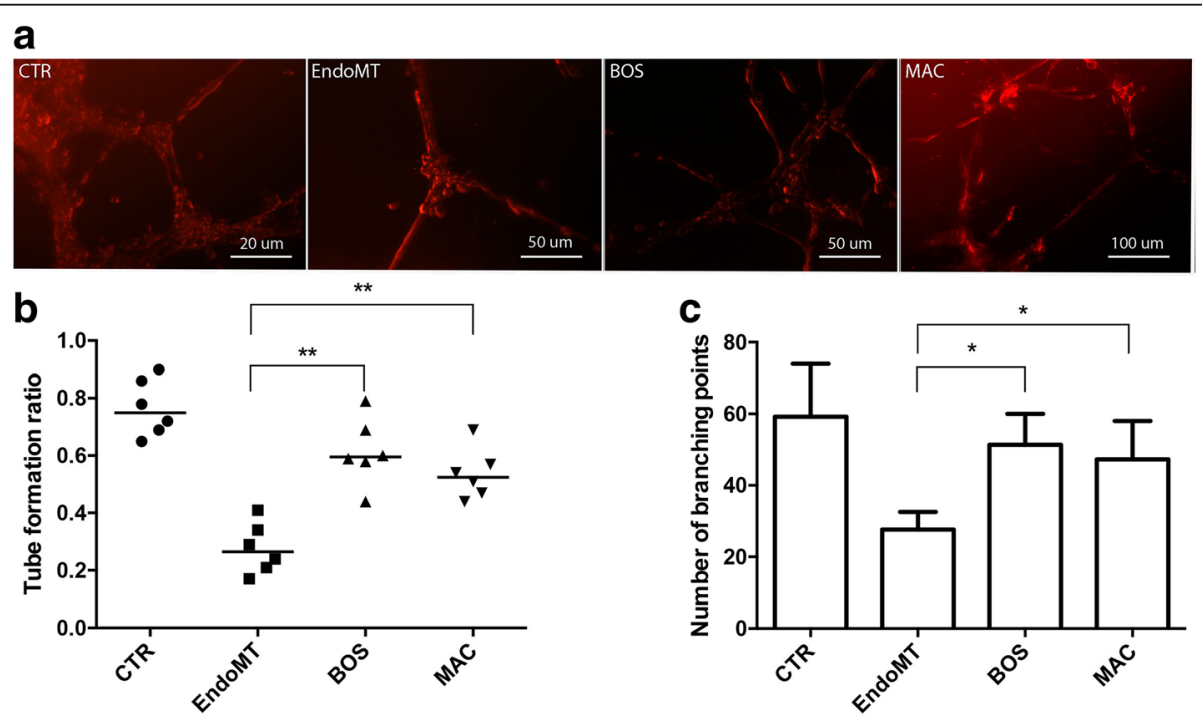

Fig. 1 a Tubular structure formation of microvascular endothelial cells (MVECs) in Matrigel after $48 \mathrm{~h}$ of culture alone (before endothelial-to-mesenchymal transition [EndoMT]) or cocultures with fibroblasts. The fluorescent red images show that MVECs (post-EndoMT) have a decreased tube formation ability with respect to those treated with bosentan (BOS) and macitentan (MAC), which show a well-organized tubelike network. $\mathbf{b}$ The tube formation ability was measured as cells per millimeter and is expressed as the ratio of total tube length in each culture condition to the length in the culture of untreated (CTR) MVECS. Data are expressed as median (range) of six biological replicates $\left({ }^{*} p<0.05,{ }^{* *} p<0.01\right)$. c Number of branching points expressed as mean \pm SD of six biological replicates $\left({ }^{*} p<0.05\right)$ 
These data were confirmed by analysis of the number of branching points (Fig. 1c) that were statistically increased when MVECs were incubated with BOS $(p<0.05)$ and MAC $(p<0.05)$.

\section{Effect of BOS and MAC on endothelial marker expression in MVECs}

As shown in Fig. 2, both BOS and MAC are able to antagonize the EndoMT process after $48 \mathrm{~h}$. In particular, $1 \mathrm{~h}$ of preincubation with $10 \mu \mathrm{M}$ BOS led to both protein $(p<0.01)$ and mRNA $(p<0.01)$ increases of CD31, and also of both protein $(p<0.01)$ and mRNA $(p<0.05)$ increases of VEGF-A. At the same time, the antiangiogenic VEGF-A165b protein $(p<0.01)$ but not mRNA levels statistically decreased. Conversely, $1 \mathrm{~h}$ of preincubation with $1 \mu \mathrm{M}$ MAC led to both protein $(p<$ $0.01)$ and mRNA $(p<0.01)$ increases of CD31, and also of both protein $(p<0.01)$ and mRNA $(p<0.01)$ increases of VEGF-A. VEGF-A165b protein $(p<0.01)$ and mRNA $(p<0.05)$ levels statistically decreased.

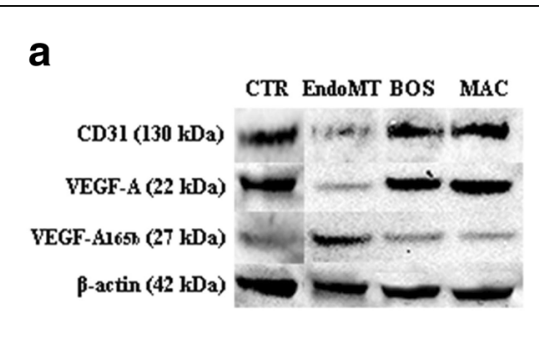

b
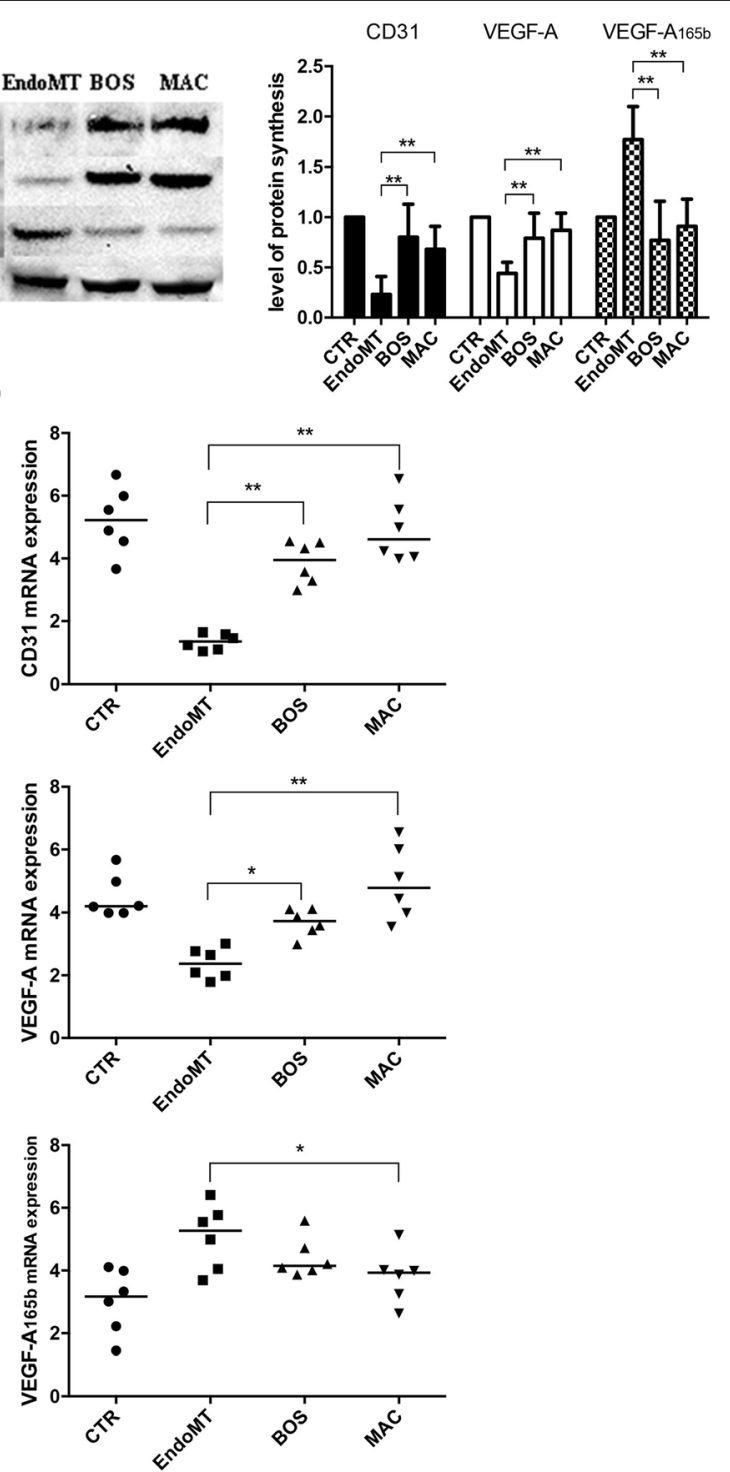

Fig. 2 a Western blot analyses (left) and the relative densitometric values (right) of cluster of differentiation 31 (CD31), vascular endothelial growth factor (VEGF)-A, and VEGF-A165b. Densitometric data are representative of three technical triplicates and are expressed as mean \pm SD. The values of protein synthesis obtained for each treatment (bosentan [BOS] and macitentan [MAC]) were normalized to that of the untreated cells (CTR) taken as unit value by definition. Analysis of variance and Tukey's multiple-comparisons test were performed for each group $\left({ }^{*} p<0.05,{ }^{* *} p<0.01\right)$. b Quantitative real-time polymerase chain reaction analyses for CD31 (top), VEGF-A (middle), and VEGF-A165b (bottom) confirm the results observed in Western blot analysis. The results are expressed as median (range) of six biological replicates $\left({ }^{*} p<0.05,{ }^{* *} p<0.01\right.$ ). $m R N A$ Messenger RNA; EndoMT Endothelial-to-mesenchymal transition 


\section{Effect of BOS and MAC on mesenchymal marker expression in MVECs}

Figure 3 shows that BOS and MAC are able to antagonize the EndoMT through the expression of typical mesenchymal markers in MVECs. In particular, BOS is responsible for both protein $(p<0.01)$ and mRNA $(p<0.05)$ decreases of $\alpha$-SMA, protein $(p<0.01)$ and mRNA $(p<0.05)$ decreases of Col I, and protein $(p<0.01)$ and mRNA $(p<0.05)$ decreases of TGF- $\beta$. MAC is responsible for both protein $(p<0.05)$ and mRNA $(p<0.05)$ decreases of $\alpha$-SMA, protein $(p<0.01)$ and mRNA $(p<$
0.01) decreases of Col-1, and protein $(p<0.05)$ and mRNA $(p<0.01)$ decreases of TGF- $\beta$.

\section{Discussion}

The in vitro experimental model of EndoMT described in the present study provides evidence that the persistence of the myofibroblast phenotype in SSc and its mediators (ET-1 and TGF- $\beta$ ) are responsible for the transdifferentiation of MVECs toward the mesenchymal phenotype $[23,24]$. As reported in the literature, the onset of SSc is represented mainly by vascular damage [4, 25], but

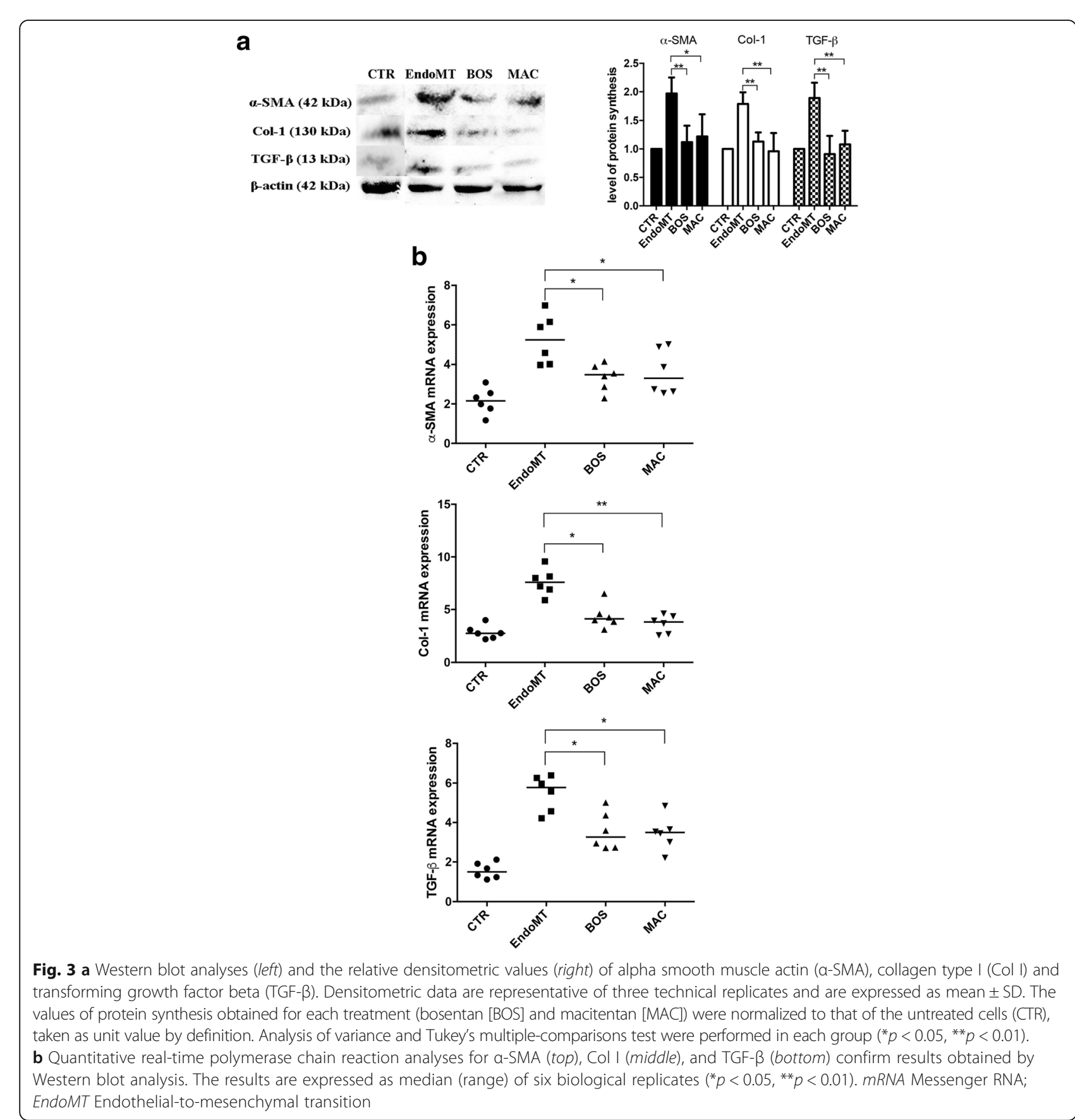


this EndoMT in vitro model could explain the persistence of fibroblast-vascular crosstalk as a profibrotic loop-promoting condition in SSc. In fact, the recruitment of myofibroblasts in affected tissues, associated with their elevated biosynthetic functions, may be considered as pivotal determinants of the extent and progression rate of the fibrosis in SSc [26]. Using a tridimensional Matrigel model, we showed the reduction of MVECs' ability to form tubular structures when cocultured with affected fibroblasts incubated with ET- 1 and TGF- $\beta$. In the same condition, it was possible to observe a switch from proangiogenic to antiangiogenic VEGF isoforms, as recently described in the literature $[27,28]$. The overexpression of VEGF165b, an inhibitory splice variant of VEGF, leads to insufficient angiogenesis in patients with SSc [29]. Not only the VEGF family but also CD31, the specific endothelial marker, seems to be downregulated after $48 \mathrm{~h}$ of coculture during the EndoMT, a condition recently described in the literature [30, 31]. MVECs lose specific endothelial markers and increase mesenchymal profibrotic markers, such as $\alpha$-SMA, Col I, and TGF- $\beta$ [32]. This evidence allowed us to hypothesize that the above-mentioned profibrotic switch may be considered a normal response of MVECs in any physiological (wound healing) [33] and pathological (SSc) [34] conditions characterized by overexpression of ET- 1 and TGF- $\beta$. In this setting, considering the synergistic action of ET-1 and TGF- $\beta$ in triggering EndoMT [35], our study strengthens the fundamental therapeutic utility that blocking the ET-1 system, by using dual endothelin-1 receptor antagonists (ERA), could represent an important therapeutic strategy [36]. Our in vitro model demonstrates that both BOS and MAC are effective in inhibiting the ET-1/TGF- $\beta$-mediated EndoMT, supporting the hypothesis that ET-1 may represent the ultimate mediator of TGF- $\beta$ actions $[37,38]$. It is very important to highlight that not only MAC but also BOS is effective in EndoMT antagonism in vitro. Therefore, it could be hypothesized that the obtained results depend more on ET-1 receptor $\left(\mathrm{ET}_{\mathrm{A}}\right.$ and $\left.\mathrm{ET}_{\mathrm{B}}\right)$ blocking than on the physiochemical and pharmacokinetic properties of the ERA used, even though a functional in vitro assay demonstrated that the potency of MAC is tenfold higher than that of the parent compound BOS [39]. Translating these preclinical findings into clinical applications, we hypothesize that the therapeutic strategy of antagonizing EndoMT could contribute to counteract endothelial dysfunction in pulmonary arterial hypertension $[40,41]$, a frequent condition in patients with SSc [42], and to counteract the steps leading to SSc digital ulcerations [43]. In fact, the remodeling effects of ERA on microvascular damage progression in patients with SSc who have undergone long-term treatment have already been demonstrated by nailfold videocapillaroscopy and laser Doppler analysis of fingertip blood flow [44-46].

\section{Conclusions}

The present study provides further in vitro evidence of the use of ERA (BOS and MAC) in inhibiting the EndoMT process, supporting the clinical efficacy of these drugs in SSc therapy and their usefulness for interfering with progressive fibrosis.

\begin{abstract}
Abbreviations
ANA: Antinuclear antibodies; ANOVA: Analysis of variance; BOS: Bosentan; CD31: Cluster of differentiation 31; CenpB: Centromere protein B; Col I: Collagen type I; EGM-MV: Microvascular endothelial cell growth medium; EMT: Epithelial-to-mesenchymal transition; ENA: Extractable nuclear antigen; EndoMT: Endothelial-to-mesenchymal transition; ERA: Dual endothelin 1 receptor antagonists; ET-1: Endothelin 1; ISSc: Limited systemic sclerosis; MAC: Macitentan; mRNA: Messenger RNA; mRSS: Modified Rodnan skin score; MVEC: Microvascular endothelial cell; P3: Third passage; PAH: Pulmonary arterial hypertension; qRT-PCR: Quantitative real-time polymerase chain reaction; SSc: Systemic sclerosis; TGF- $\beta$ : Transforming growth factor beta; VEGF: Vascular endothelial growth factor; $a-S M A$ : Alpha-smooth muscle actin
\end{abstract}

\section{Acknowledgements}

The authors thank Dr. Yongqing Wang of the University of Toledo Department of Medicine for his technical assistance.

\section{Funding}

Not applicable.

\section{Availability of data and materials Not applicable.}

\section{Authors' contributions}

CCo conceived of and designed the study, performed the literature search, interpreted the data, created the figures, and wrote and revised the manuscript. MC conceived of and designed the study, interpreted the data, and wrote and revised the manuscript. BK conceived of and designed the study, interpreted the data, performed the literature search, and wrote and revised the manuscript. GP conceived of and designed the study, performed the literature search and statistical analysis, and revised the manuscript. AM collected and interpreted the data and revised the manuscript. CCh performed the literature search, collected and interpreted the data, and revised the manuscript. SS collected and interpreted the data, performed the statistical analysis, and revised the manuscript. RN designed the study, interpreted the data, and revised the manuscript. NG conceived of and designed the study, collected and interpreted the data, performed the literature search, and wrote and revised the manuscript. All authors read and approved the final manuscript, and all authors agree to be accountable for all aspects of the study.

\section{Competing interests}

The authors declare that they have no competing interests.

\section{Consent for publication}

All patients signed written informed consent forms to allow publication of their data in this article.

\section{Ethics approval and consent to participate}

All patients gave their fully informed, voluntary, written consent according to the principles of the Declaration of Helsinki and in compliance with the ethics committee of the University of Siena, whose institutional review board approved the entire study protocol.

\section{Author details}

${ }^{1}$ Scleroderma Unit, Department of Medicine, Surgery and Neurosciences, University of Siena, 53100 Siena, Italy. ${ }^{2}$ Research Laboratory and Academic Division of Clinical Rheumatology, Department of Internal Medicine, Institute for Research and Health Care (IRCCS), University of Genoa, San Martino, Genoa, Italy. ${ }^{3}$ Division of Rheumatology and Immunology, College of Medicine, University of Toledo, Toledo, OH, USA. ${ }^{4}$ Medical and Scientific Direction, Actelion Pharmaceuticals Italy, Imola, Italy. 
Received: 16 May 2016 Accepted: 16 September 2016 Published online: 06 October 2016

\section{References}

1. Denton CP. Advances in pathogenesis and treatment of systemic sclerosis. Clin Med (Lond). 2016;16:55-60

2. Cutolo M, Sulli A, Smith V. Evaluating microangiopathy in systemic sclerosis: what have we learnt and what is left to discover? Expert Rev Clin Immunol. 2011;7:395-7.

3. Allanore $Y$, Distler O. Systemic sclerosis in 2014: advances in cohort enrichment shape future of trial design. Nat Rev Rheumatol. 2015;11:72-4.

4. Matucci-Cerinic M, Kahaleh B, Wigley FM. Review: evidence that systemic sclerosis is a vascular disease. Arthritis Rheum. 2013;65:1953-62.

5. Herrick AL, Illingworth K, Blann A. von Willebrand factor, thrombomodulin, thromboxane, thromboglobulin and markers of fibrinolysis in primary Raynaud's phenomenon and systemic sclerosis. Ann Rheum Dis. 1996:55:122-27.

6. Cipriani P, Di Benedetto P, Ruscitti P, Capece D, Zazzeroni F, Liakouli V, et al. The endothelial-mesenchymal transition in systemic sclerosis is induced by endothelin-1 and transforming growth factor- $\beta$ and may be blocked by macitentan, a dual endothelin-1 receptor antagonist. J Rheumatol. 2015:42:1808-16.

7. Cipriani P, Di Benedetto P, Ruscitti P, Campese AF, Liakouli V, Carubbi F, et al. Impaired endothelium-mesenchymal stem cells cross-talk in systemic sclerosis: a link between vascular and fibrotic features. Arthritis Res Ther. 2014;16:442

8. Piera-Velazquez S, Li Z, Jimenez SA. Role of endothelial-mesenchymal transition (EndoMT) in the pathogenesis of fibrotic disorders. Am J Pathol. 2011;179:1074-80

9. Piera-Velazquez S, Mendoza FA, Jimenez SA. Endothelial to mesenchymal transition (EndoMT) in the pathogenesis of human fibrotic diseases. J Clin Med. 2016;5:45.

10. Chen PY, Qin L, Baeyens N, Li G, Afolabi T, Budatha M, et al. Endothelial-tomesenchymal transition drives atherosclerosis progression. J Clin Invest. 2015:125:4514-28

11. Arciniegas E, Frid MG, Douglas IS, Stenmark KR. Perspectives on endothelialto-mesenchymal transition: potential contribution to vascular remodeling in chronic pulmonary hypertension. Am J Physiol Lung Cell Mol Physiol. 2007;293:L1-8.

12. Li J, Bertram JF. Endothelial-myofibroblast transition, a new player in diabetic renal fibrosis. Nephrology (Carlton). 2010;15:507-12.

13. Fu Y, Chang A, Chang L, Niessen K, Eapen S, Setiadi A, et al. Differential regulation of transforming growth factor beta signaling pathways by Notch in human endothelial cells. J Biol Chem. 2009;284:19452-62.

14. Zeisberg EM, Potenta S, Xie L, Zeisberg M, Kalluri R. Discovery of endothelial to mesenchymal transition as a source for carcinoma-associated fibroblasts. Cancer Res. 2007;67:10123-8.

15. Lafyatis R. Transforming growth factor $\beta$-at the centre of systemic sclerosis. Nat Rev Rheumatol. 2014;10:706-19.

16. Rodríguez-Pascual F, Busnadiego O, González-Santamaría J. The profibrotic role of endothelin-1: is the door still open for the treatment of fibrotic diseases? Life Sci. 2014;118:156-64.

17. Ahmedat AS, Warnken M, Seemann WK, Mohr K, Kostenis E, Juergens UR, et al. Pro-fibrotic processes in human lung fibroblasts are driven by an autocrine/ paracrine endothelinergic system. Br J Pharmacol. 2013;168:471-87.

18. Leroy EC, Black C, Fleischmajer R, Jablonska S, Krieg T, Medsger Jr TA, et al. Scleroderma (systemic sclerosis): classification, subsets and pathogenesis. J Rheumatol. 1988;15:202-5.

19. van den Hoogen F, Khanna D, Fransen J, Johnson SR, Baron M, Tyndall A, et al. 2013 classification criteria for systemic sclerosis: an American College of Rheumatology/European League against Rheumatism collaborative initiative. Arthritis Rheum. 2013;65:2737-47.

20. Clements PJ, Lachenruch PA, Nq SC, Simmons M, Sterz M, Furst DE. Skin score: a semiquantitative measure of cutaneous involvement that improves prediction of prognosis in systemic sclerosis. Arthritis Rheum. 1990:33:1256-63.

21. Bradford MM. A rapid and sensitive method for the quantitation of microgram quantities of protein utilizing the principle of protein-dye binding. Anal Biochem. 1976;72:48-254.

22. Laemmli UK. Cleavage of structural proteins during the assembly of the head of bacteriophage T4. Nature. 1970;227:680-5.
23. Frid MG, Kale VA, Stenmark KR. Mature vascular endothelium can give rise to smooth muscle cells via endothelial-mesenchymal transdifferentiation: in vitro analysis. Circ Res. 2002;90:1189-96.

24. Arciniegas E, Sutton AB, Allen TD, Schor AM. Transforming growth factor beta 1 promotes the differentiation of endothelial cells into smooth muscle-like cells in vitro. J Cell Sci. 1992;103:521-9.

25. Kahaleh B. The microvascular endothelium in scleroderma. Rheumatology (Oxford). 2008:47 Suppl 5:v14-5.

26. Jimenez SA. Role of endothelial to mesenchymal transition in the pathogenesis of the vascular alterations in systemic sclerosis. ISRN Rheumatol. 2013:2013:835948.

27. Manetti M, Guiducci S, Romano E, Bellando-Randone S, Lepri G, Bruni C, et al. Increased plasma levels of the VEGF165b splice variant are associated with the severity of nailfold capillary loss in systemic sclerosis. Ann Rheum Dis. 2013:72:1425-7.

28. Harris S, Craze M, Newton J, Fisher M, Shima DT, Tozer GM, et al. Do anti-angiogenic VEGF (VEGFxxxb) isoforms exist? A cautionary tale. PLoS One. 2012;7:e35231

29. Manetti M, Guiducci S, Romano E, Ceccarelli C, Bellando-Randone S, Conforti $M L$, et al. Overexpression of VEGF165b, an inhibitory splice variant of vascular endothelial growth factor, leads to insufficient angiogenesis in patients with systemic sclerosis. Circ Res. 2011;109:e14-26.

30. Manetti M, Rosa I, Milia AF, Guiducci S, Carmeliet P, Ibba-Manneschi L, et al. Inactivation of urokinase-type plasminogen activator receptor (UPAR) gene induces dermal and pulmonary fibrosis and peripheral microvasculopathy in mice: a new model of experimental scleroderma? Ann Rheum Dis. 2014;73:1700-9

31. Mendoza FA, Piera-Velazquez S, Farber JL, Feghali-Bostwick C, Jiménez SA Endothelial cells expressing endothelial and mesenchymal cell gene products in lung tissue from patients with systemic sclerosis-associated interstitial lung disease. Arthritis Rheumatol. 2016;68:210-7.

32. Soldano S, Montagna P, Brizzolara R, Seriolo B, Sulli A, Cutolo M. Endothelialto- mesenchymal transition in cultured human dermal microvascular endothelial cells: effects of endothelin-1 [abstract]. Ann Rheum Dis. 2013;72 Suppl 3:186.

33. Lagares D, García-Fernández RA, Jiménez CL, Magán-Marchal $N$, Busnadiego O, Lamas S, et al. Endothelin 1 contributes to the effect of transforming growth factor $\beta 1$ on wound repair and skin fibrosis. Arthritis Rheum. 2010;62:878-89.

34. Cipriani $P$, Di Benedetto $P$, Ruscitti $P$, Verzella D, Fischietti M, Zazzeroni $F$, et al. Macitentan inhibits the transforming growth factor- $\beta$ profibrotic action, blocking the signaling mediated by the ETR/TRRI complex in systemic sclerosis dermal fibroblasts. Arthritis Res Ther. 2015:17:247.

35. Horstmeyer A, Licht C, Scherr G, Eckes B, Krieg T. Signalling and regulation of collagen I synthesis by ET-1 and TGF-beta1. FEBS J. 2005:272:6297-309.

36. Cutolo M, Sulli A. Therapy: optimized treatment algorithms for digital vasculopathy in SSc. Nat Rev Rheumatol. 2015;11:569-71.

37. Shi-Wen X, Rodríguez-Pascual F, Lamas S, Holmes A, Howat S, Pearson JD, et al. Constitutive ALK5-independent c-Jun N-terminal kinase activation contributes to endothelin-1 overexpression in pulmonary fibrosis: evidence of an autocrine endothelin loop operating through the endothelin $A$ and $B$ receptors. Mol Cell Biol. 2006;26:5518-27.

38. Cutolo M, Sulli A, Pizzorni C, Paolino S, Smith V. Systemic sclerosis: markers and targeted treatments. Acta Reumatol Port. 2016;41:18-25.

39. Iglarz M, Binkert C, Morrison K, Fischli W, Gatfield J, Treiber A, et al. Pharmacology of macitentan, an orally active tissue-targeting dual endothelin receptor antagonist. J Pharmacol Exp Ther. 2008;327:736-45

40. Good RB, Gilbane AJ, Trinder SL, Denton CP, Coghlan G, Abraham DJ, et al. Endothelial to mesenchymal transition contributes to endothelial dysfunction in pulmonary arterial hypertension. Am J Pathol. 2015;185:1850-8.

41. Ranchoux B, Antigny F, Rucker-Martin C, Hautefort A, Péchoux C, Bogaard $\mathrm{HJ}$, et al. Endothelial-to-mesenchymal transition in pulmonary hypertension. Circulation. 2015;131:1006-18.

42. Jimenez SA, Piera-Velazquez S. Endothelial to mesenchymal transition (EndoMT) in the pathogenesis of systemic sclerosis-associated pulmonary fibrosis and pulmonary arterial hypertension: myth or reality? Matrix Biol. 2016;51:26-36

43. Khanna D, Denton CP, Merkel PA, Krieg T, Le Brun FO, Marr A et al. Effect of macitentan on the development of new ischemic digital ulcers in patients with systemic sclerosis: DUAL-1 and DUAL-2 randomized clinical trials. JAMA. 2016;15:1975-88. 
44. Guiducci S, Bellando Randone S, Bruni C, Carnesecchi G, Maresta A, lannone F, et al. Bosentan fosters microvascular de-remodelling in systemic sclerosis. Clin Rheumatol. 2012;31:1723-5.

45. Cutolo M, Ruaro B, Pizzorni C, Ravera F, Smith V, Zampogna G, et al. Longterm treatment with endothelin receptor antagonist bosentan and iloprost improves fingertip blood perfusion in systemic sclerosis. J Rheumatol. 2014:41:881-6.

46. Cutolo M, Zampogna G, Vremis L, Smith V, Pizzorni C, Sulli A. Longterm effects of endothelin receptor antagonism on microvascular damage evaluated by nailfold capillaroscopic analysis in systemic sclerosis. J Rheumatol. 2013:40:40-5.

Submit your next manuscript to BioMed Central and we will help you at every step:

- We accept pre-submission inquiries

- Our selector tool helps you to find the most relevant journal

- We provide round the clock customer support

- Convenient online submission

- Thorough peer review

- Inclusion in PubMed and all major indexing services

- Maximum visibility for your research

Submit your manuscript at www.biomedcentral.com/submit
Biomed Central 